\title{
Collagen Degradation and the Response to Parathyroid Extract in the Intact Rhesus Monkey*
}

\author{
Louis V. Avioli $†$ And Darwin J. Prockop \\ (From the Department of Medicine, Washington University School of Medicine and the \\ Jewish Hospital of St. Louis, St. Louis, Mo., and the Departments of Medicine and \\ Biochemistry, University of Pennsylvania and the Philadelphia General \\ Hospital, Philadelphia, Pa.)
}

\begin{abstract}
Summary. Proline $-{ }^{14} \mathrm{C}$ was administered to five adult rhesus monkeys, and the degradation of collagen was followed by the excretion of hydroxyproline${ }^{14} \mathrm{C}$. The results suggested the presence of at least three separate pools of collagen with half-lives of 1 to 2,2 to 3 , and 50 to 70 days. The monkeys were killed after 44 days; at that time the specific activity of the hydroxyproline $-{ }^{14} \mathrm{C}$ in urine was found to be four to five times that of the hydroxyproline in soluble collagen and 81 to $93 \%$ that of hydroxyproline in insoluble collagen. The relationships between urinary hydroxyproline and the degradation of collagen were similar to those previously demonstrated in rats.

Parathyroid hormone was administered daily to two of the monkeys from the 27 th to the 44th day of the study. The parathyroid hormone increased the amount of hydroxyproline $-{ }^{14} \mathrm{C}$ excreted, but there was no significant change in the specific activity of the urinary hydroxyproline $-{ }^{14} \mathrm{C}$. Since under the conditions of the experiment insoluble collagen was the only possible source of hydroxyproline ${ }^{14} \mathrm{C}$ of relatively high specific activity, the results indicated that parathyroid hormone directly or indirectly increased the degradation of insoluble collagen. The results also suggested that parathyroid hormone increased the degradation of soluble collagen, but the relative magnitude of this effect was not clearly established.
\end{abstract}

\section{Introduction}

Hydroxyproline accounts for approximately $14 \%$ of the total amino acid content of collagen, and except for small amounts in elastin, no significant amounts of the amino acid are found in any other body protein. Recent studies have sub-

* Submitted for publication June 30, 1966; accepted October 20, 1966.

Supported in part by U. S. Public Health Service grants 06404 and FR-00107 from the National Institutes of Health and by Atomic Energy Commission contract AT(30-1)-3174. A preliminary report of this work has been presented (1).

$\dagger$ Career Research Development awardee of the $\mathrm{Na}$ tional Institute of General Medical Sciences (6-K3-GM22, 676-O1A1).

Address requests for reprints to Dr. Louis V. Avioli, Jewish Hospital, 216 S. Kingshighway, St. Louis, Mo. 63110. stantiated earlier suggestions (2) that essentially all the hydroxyproline in animal tissues is synthesized by the hydroxylation of a proline-rich polypeptide precursor of collagen $(3,4)$. These relationships suggest that the presence of hydroxyproline in tissues or biological fluids directly reflects the presence of collagen or of degradative products of collagen. Peptides containing hydroxyproline are normally excreted in the urine of animals and man (5), and the amino acid composition of the urinary peptides (6) as well as the results of isotopic studies in rats $(7,8)$ suggests that the excretion of peptide hydroxyproline can be used to follow the degradation of collagen in vivo. Increases in hydroxyproline excretion have been observed in experimental and clinical conditions where the rate of collagen degradation is increased, and decreases in hydroxyproline ex- 
TABLE I

The effect of parathyroid extract (PTE) on urinary hydroxyproline, urinary proline, and serum calcium

\begin{tabular}{|c|c|c|c|c|c|c|c|c|}
\hline \multirow[b]{2}{*}{ Monkey } & \multicolumn{4}{|c|}{ Before PTE* } & \multicolumn{4}{|c|}{ During PTE† } \\
\hline & Hypro & Pro & $\begin{array}{l}\text { Hypro/ } \\
\text { pro }\end{array}$ & $\begin{array}{l}\text { Serum } \\
\text { calcium }\end{array}$ & Hypro & Pro & $\begin{array}{c}\text { Hypro/ } \\
\text { pro }\end{array}$ & $\begin{array}{l}\text { Serum } \\
\text { calcium }\end{array}$ \\
\hline & $m g / 24 h r$ & $m g / 24 h r$ & & $m g / 100 m l$ & $m g / 24 h r$ & $m g / 24 h r$ & & $m g / 100 \mathrm{ml}$ \\
\hline I & $4.70 \pm 0.41$ & $8.07 \pm 0.52$ & 0.58 & $8.5-10.3(15)$ & & & & \\
\hline II & $5.26 \pm 0.31$ & $9.39 \pm 0.32$ & 0.56 & $9.4-10.9(16)$ & & & & \\
\hline III & $5.29 \pm 0.42$ & $9.81 \pm 0.17$ & 0.53 & $8.7-9.7(12)$ & & & & \\
\hline IV\$ & $4.36 \pm 0.71$ & $8.62 \pm 0.88$ & 0.51 & $8.9-10.7(13)$ & $7.02 \pm 0.35$ & $12.27 \pm 0.59$ & 0.57 & $10.9-12.3(8)$ \\
\hline$V \S$ & $4.42 \pm 0.64$ & $8.15 \pm 0.59$ & 0.54 & $8.8-10.6(13)$ & $7.36 \pm 0.47$ & $13.06 \pm 0.17$ & 0.56 & $10.7-13.0(7)$ \\
\hline
\end{tabular}

* Values represent the mean \pm standard error of 44 consecutive determinations in monkeys I to III and 26 consecutive determinations in monkeys IV and V.

$\dagger$ Values represent the mean \pm standard error of 17 consecutive determinations.

₹ange of serum calciums. Number of determinations noted in parentheses.

$\$ \mathrm{PTE}$ from 27 to 44 days.

cretion have been seen in conditions where collagen degradation is decreased (for reviews see $9,10)$. About half of body collagen is found in bone, and some of the largest changes in hydroxyproline excretion have been seen in bone diseases (11). Increased excretion of peptide hydroxyproline has been reported in some patients with hyperparathyroidism and also after administration of parathyroid hormone to man (11-17). In several patients a decreased excretion of hydroxyproline has been observed after successful removal of parathyroid adenomata $(14,17)$.

The increased amounts of hydroxyproline that appear in urine after administration of parathyroid hormone probably originate from the resorption of bone collagen, but the mechanism of this effect is not clear, since the hydroxyproline peptides could arise from the degradation of recently synthesized forms of collagen, such as soluble collagen (18), or they could originate from the degradation of more mature insoluble forms of collagen. In the present study, the effects of parathyroid hormone on bone collagen were examined by labeling the hydroxyproline $-{ }^{14} \mathrm{C}$ in collagen with proline $-{ }^{14} \mathrm{C}$ and then administering parathyroid hormone. Since the heavy body burden imposed by the administration of proline $-{ }^{14} \mathrm{C}$ limits the use of this technique in man, adult rhesus monkeys (Macaca mulatta) were used for these experiments.

\section{Methods}

Five adult male captive rhesus monkeys (numbered $\mathrm{I}$ to $\mathrm{V}$ ) were placed in individual air-conditioned cages designed for metabolic studies with radioactive isotopes.
The health of the animals had been previously ensured by a 90-day quarantine period, periodic tuberculin skin tests, chest films, and complete blood count. Their individual body weights ranged from 4.2 to $5.3 \mathrm{~kg}$. The ages of these monkeys, based on Van Wagenen and Catchpole's body weight to age relationships (19), ranged between 36 and 44 months.

During a 5-week acclimatization period and the subsequent 6-week experimental period, the monkeys were fed a nutritionally adequate low hydroxyproline diet, which contained $6.6 \mathrm{~g}$ protein, $2.0 \mathrm{~g}$ fat, $127 \mathrm{~g}$ carbohydrate, $136 \mathrm{mg}$ calcium, $168 \mathrm{mg}$ phosphorus, $8.4 \mathrm{mg}$ sodium, $50 \mathrm{mEq}$ potassium, $14 \mathrm{mEq}$ magnesium, and a total of 495 calories. On alternate days the diets were supplemented by $0.6 \mathrm{ml}$ multivitamin drops, ${ }^{1}$ and at all times distilled water intake was ad libitum. On the day of isotope administration each monkey was injected intravenously with $300 \mu \mathrm{c}$ of uniformly labeled proline $-{ }^{14} \mathrm{C} 2$ (specific activity $>180 \mathrm{mc}$ per mmole) in $1 \mathrm{ml}$ of $0.9 \%$ $\mathrm{NaCl}$. The urinary excretion of stable and radioactive proline and hydroxyproline was then followed for the subsequent 44 days. Urine was collected under toluene at 24-hour intervals in ice-cooled containers and assayed directly for proline (20), hydroxyproline (21), and hydroxyproline $-{ }^{14} \mathrm{C}$ specific activity (22). Because samples collected during the first 5 days after isotope administration contained large amounts of proline $-{ }^{14} \mathrm{C}$, the hydroxyproline in these samples was separated from proline on a cation exchange resin column before assay (22). Plasma samples were obtained at 4- to 5-day intervals, and total calcium was measured with a flame spectrophotometric technique (23).

Twenty-seven days after the initial proline $-{ }^{14} \mathrm{C}$ injections, monkeys IV and $\mathrm{V}$ were given $200 \mathrm{U}$ of commercial parathyroid extract ${ }^{3}$ daily intramuscularly in two divided doses. The injections were continued in each monkey until the 44th day, and on the 44th day after the proline $-{ }^{14} \mathrm{C}$ injection all the monkeys were sacrificed.

1 Vipenta, Roche Laboratories, Nutley, N. J.

2 New England Nuclear Corp., Boston, Mass.

3 Eli Lilly \& Co., Indianapolis, Ind. 
Duplicate samples of 20 to $50 \mathrm{~g}$ shaved skin, femoral bone, and humeral bone were obtained. The skin was minced in small 2-mm segments with surgical razors, and the bone marrow was removed from the bones by curettage. The bone specimens were blotted, cut into 1 - to 2-cm strips by hand with orthopedic bone cutters, and homogenized into bone powder with a mortar and pestle. The samples were then immediately placed in 5 vol of $0.14 \mathrm{M} \mathrm{NaCl}$, and the soluble collagen fractions extracted on a rotary shaker at $4^{\circ} \mathrm{C}$ for 48 hours. After $\mathrm{NaCl}$ extraction, the samples were centrifuged at $30,000 \times$ $g$ for 2 hours, and the supernatant solutions were removed for assay of soluble collagen hydroxyproline- ${ }^{14} \mathrm{C}$ specific activity according to previously published techniques (22). The residues were extracted three times with 5 vol of absolute ethanol and then with 5 vol of boiling ethanol: ether $(1: 2)$ to remove the lipids. The insoluble collagen in the residues was solubilized as gelatin by adding 20 vol of distilled water and autoclaving at $126^{\circ}$ for 1 hour. Fractions of the gelatinized insoluble collagen were hydrolyzed with equal volumes of concentrated $\mathrm{HCl}$ at $120^{\circ}$ for 18 hours, evaporated to dryness, and assayed for hydroxyproline content (20) and for hydroxyproline- ${ }^{14} \mathrm{C}$ specific activity (22). The counting efficiency for the liquid scintillation counter employed was $66 \%$, and the background was $21 \mathrm{cpm}$. In each instance observed counts per minute were converted to disintegrations per minute by reference to benzoic acid- ${ }^{14} \mathrm{C}$ standards (U. S. National Bureau of Standards). All reported values for hydroxyproline $-{ }^{14} \mathrm{C}$ were based on observed counts per minute, which were at least ten times the background of the counting system; assays of duplicate samples agreed with $\pm 5 \%$ of the mean.

\section{Results}

Urinary hydroxyproline and effects of parathyroid extract $(P T E)$. The mean urinary hydroxyproline values of 44 consecutive determinations in the control animals (monkeys I to III, Table I)

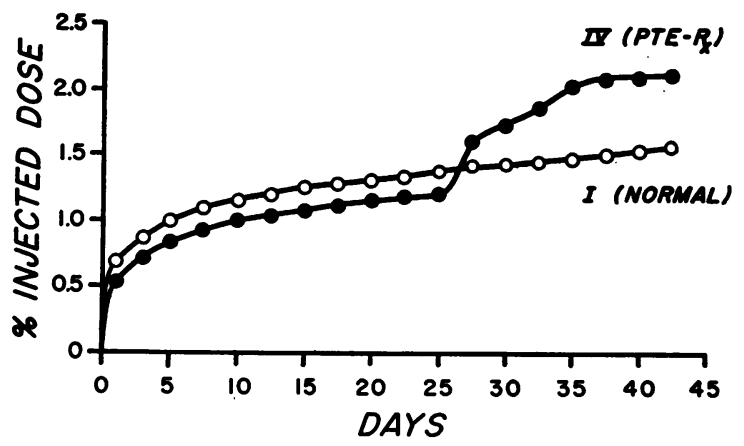

Fig. 1. Cumulative ${ }^{14} \mathrm{C}$ excretion in monkeys I AND IV AFter INJECtion of Proline- ${ }^{14} \mathrm{C}$. Parathyroid extract (PTE) therapy was initiated on the 27 th day in monkey IV and continued for the subsequent 17-day period.

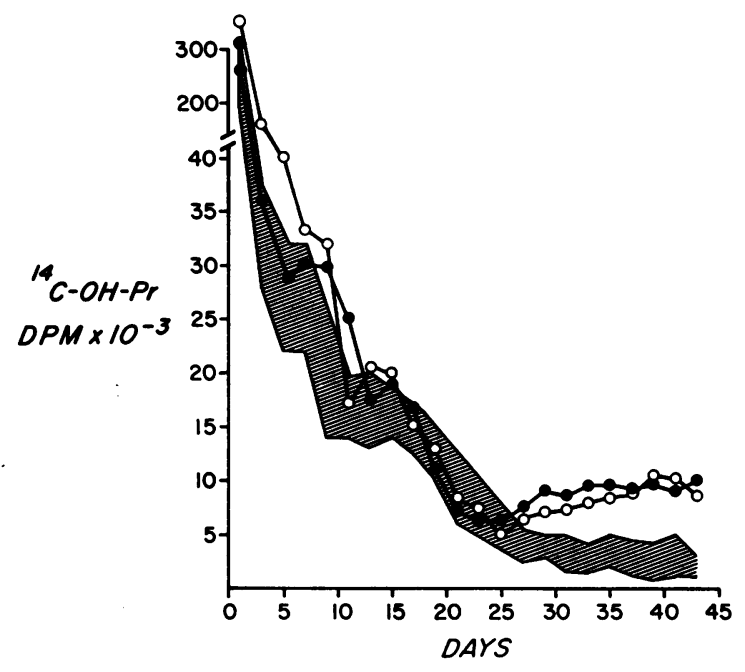

Fig. 2. HYDROXYPROLINE- ${ }^{14} \mathrm{C}$ EXCRETION IN CONTROL (MONKEYS I TO III) AND PTE-TREATED (MONKEYS IV AND V) ANIMALS AFTER THE INJECTION OF PROLINE ${ }^{14} \mathrm{C}$. The shaded area represents the range obtained in the control animals. The closed circles refer to monkey $\mathrm{V}$ and the open circles monkey IV. PTE therapy was given between the 27th and 44th days in monkeys IV and V. ${ }^{14} \mathrm{C}-\mathrm{OH}-\mathrm{Pr}=$ hydroxyproline $-{ }^{14} \mathrm{C}$.

and of 26 consecutive determinations in the PTEtreated animals before therapy (monkeys IV and $\mathrm{V}$, Table I) ranged from 4.36 to $5.29 \mathrm{mg}$ per 24 hours. Mean urinary proline excretion of the same specimens ranged between 8.07 and $9.81 \mathrm{mg}$ per 24 hours. The average ratio of hydroxyproline to proline in urine in the control and PTEtreated monkeys before therapy ranged from 0.51 to 0.58 (Table I). PTE administration to monkeys IV and V resulted in a 61 and $66 \%$ increase, respectively, in mean urinary hydroxyproline, and a 42 and $60 \%$ increase in mean urinary proline. There was no significant change in the ratio of hydroxyproline to proline in urine.

The cumulative 44 -day excretion of ${ }^{14} \mathrm{C}$ in the three control monkeys after the injection of proline $-{ }^{14} \mathrm{C}$ ranged from 1.56 to $1.89 \%$ of the injected radioactivity. As indicated in Figure 1 for monkey $\mathrm{I}$, one-third of the total ${ }^{14} \mathrm{C}$ recovered in urine was excreted in the first day and about twothirds in the first 5 days. Proline $-{ }^{14} \mathrm{C}$ accounted for over $90 \%$ of the total ${ }^{14} \mathrm{C}$ in the urine for the first 5 days, and the specific activity of the urinary proline- ${ }^{14} \mathrm{C}$ during this period decreased with a half-life of 1.2 to 2.0 days in the five monkeys. On the first day of PTE administration a prompt and 


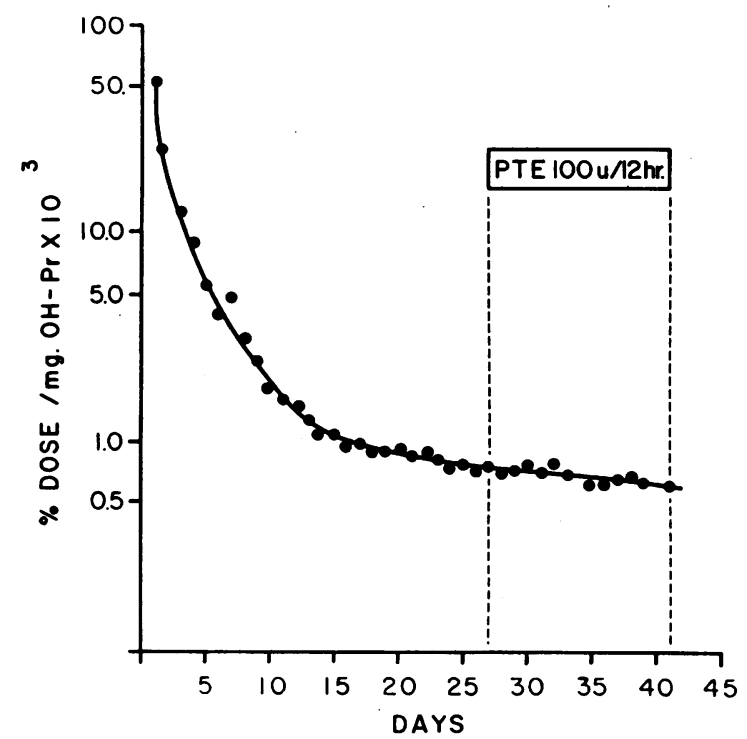

Fig. 3. SPECIFIC ACTIVITY OF URINARY HYDROXYPROLINE AFTER INJECTION OF PROLINE- ${ }^{14} \mathrm{C}$ INTO MONKEY IV. A similar curve was obtained for PTE-treated monkey V.

sustained rise in total ${ }^{14} \mathrm{C}$ excretion was observed in monkey IV. With this increase the cumulative 44-day ${ }^{14} \mathrm{C}$ excretion increased to $2.1 \%$ of the injected dose (Figure 1). A similar response was observed after administration of PTE to monkey $\mathrm{V}$, and in this monkey the cumulative ${ }^{14} \mathrm{C}$ excretion increased to $2.4 \%$.

Figure 2 illustrates the range of urinary hydroxyproline $-{ }^{14} \mathrm{C}$ excretion of control monkeys I to III and the daily values for urinary hydroxyproline $-{ }^{14} \mathrm{C}$ of monkeys IV and $\mathrm{V}$ during PTE administration. After the initial labeling of collagenous hydroxyproline, a gradual fall in hydroxyproline $-{ }^{14} \mathrm{C}$ excretion was observed in the control animals for the first 25 days, but relatively constant excretion occurred thereafter. The hydroxyproline- ${ }^{14} \mathrm{C}$ excretion patterns of monkeys IV and V before PTE were similar to those of the control monkeys. PTE induced a prompt rise in the amount of hydroxyproline $-{ }^{14} \mathrm{C}$ excreted by monkeys IV and $\mathrm{V}$ that was sustained during the 2 -week treatment period. The hydroxyproline $-{ }^{14} \mathrm{C}$ in urine increased from 0.24 to $0.29 \%$ of the injected dose in control animals to 0.39 and $0.40 \%$ of the injected dose in PTE-treated animals.

In spite of the increase in the amount of hydroxyproline $-{ }^{14} \mathrm{C}$ excreted after administration of parathyroid hormone, there was no significant ef- fect on the specific activity of the urinary hydroxyproline- ${ }^{14} \mathrm{C}$ (Table III). The values of 0.85 and $0.87 \mathrm{dpm}$ per $\mu \mathrm{g}$ of the PTE-treated animals were well within the control range of 0.82 to $0.92 \mathrm{dpm}$ per $\mu \mathrm{g}$. Also, throughout the treatment period of days 27 to 44 the specific activity of urinary hydroxyproline $-{ }^{14} \mathrm{C}$ decreased at about the same rate as in control animals (Figure 3 ).

Decay rates of urinary hydroxyproline $-{ }^{14} \mathrm{C}$. Inspection of the semilogarithmic plot of the specific activities of the urinary hydroxyproline against time suggested that the curves could be resolved into a series of decreasing exponential functions, which might represent discrete hydroxyproline pools within the body (7). The 44-day urinary hydroxyproline specific activity data for the control monkeys I, II, and III were combined and a single composite curve was defined (Figure 4). Graphical analysis (7) of the composite urinary specific activity curves in terms of exponential components approximated the data analytically to a sum of three exponentials of the form:

$$
\mathrm{X}_{1}=a_{11} \mathrm{e}^{-\alpha_{1} t}+a_{12} \mathrm{e}^{-\alpha_{2} t}+a_{13} \mathrm{e}^{-\alpha_{3} t},
$$

where $X_{1}$ is the specific activity of the urinary hydroxyproline in per cent dose per milligram hydroxyproline; $a_{11}, a_{12}$, and $a_{13}$ are the ordinate intercepts of the three exponential components (Fig-

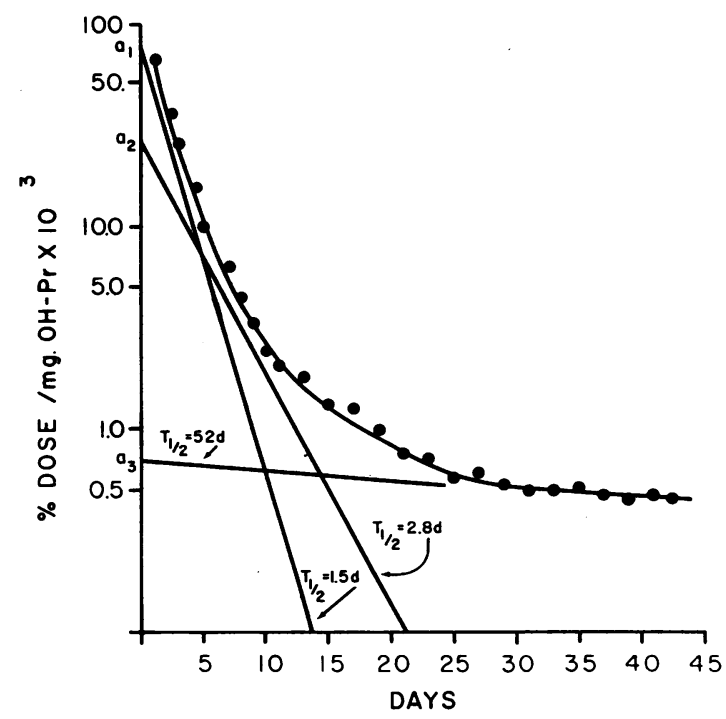

Fig. 4. CoMposite URINARY HYDROXYPROLINE- ${ }^{14} \mathrm{C}$ SPECIFIC ACTIVITY CURVE BASED ON THE AVERAGE VALUES OF THE POINTS FOR MONKEYS I, II, AND III. $\mathrm{X}_{1}=$ $0.00074 \mathrm{e}^{-0.462 t}+0.00018 \mathrm{e}^{-0.248 \mathrm{t}}+0.00008 \mathrm{e}^{-0.013 t}, \quad a_{1}, a_{2}$, and $a_{3}$ refer to the ordinate intercepts noted in the text. 
ure 4); $\alpha_{1}, \alpha_{2}$, and $\alpha_{3}$ are the fractional disappearance rate constants equal to 0.693 divided by the half-life in days; and $t$ is the time in days. The values for $a$ and $\alpha$ obtained from the composite curve of control monkeys I to III are given in the legend to Figure 4. Individual analysis of the derived exponential components of semilogarithmic specific activity decay curves of monkeys I to III yielded a slow component of 58 to 66 days half-time accounting for 21 to $35 \%$ of the total urinary hydroxyproline $-{ }^{14} \mathrm{C}$, and two more rapid components with 1- and 3-day half-times, respectively, each accounting for 50 and $20 \%$ of the total urinary hydroxyproline ${ }^{14} \mathrm{C}$ (Table II). The half-times of the three components calculated from the hydroxyproline $-{ }^{14} \mathrm{C}$ data of PTE-treated animals were similar to those of the control group.

In order to test whether the exponential expression derived from graphic analysis of urinary hydroxyproline ${ }^{14} \mathrm{C}$ specific activity curves (Figure 4) adequately described the data, we integrated the exponential components noted in Equation 1, e.g.,

and

$$
\mathrm{dU}=a_{11} \mathrm{e}^{-\alpha_{1} \mathrm{t}}+a_{12} \mathrm{e}^{\alpha_{2} \mathrm{t}}+a_{13} \mathrm{e}^{-\alpha_{3} \mathrm{t}},
$$

$$
\mathrm{U}=\int_{0}^{\infty} \mathrm{dU}=\frac{a_{11}}{\alpha_{1}}+\frac{a_{12}}{\alpha_{2}}+\frac{a_{13}}{\alpha_{3}} .
$$

The results were compared to the observed 44day cumulative hydroxyproline $-{ }^{14} \mathrm{C}$ excretion ( $\mathrm{Ta}-$ ble II). The calculated cumulative hydroxyproline $-{ }^{14} \mathrm{C}$ values were 5 to $17 \%$ greater than the quantities recovered experimentally. This discrepancy is probably explained by errors intrinsic to extrapolating the data beyond the last measurement in the initial graphic analysis.

Comparison of the hydroxyproline ${ }^{14} \mathrm{C}$ in collagen and urine. A comparison of the specific ac-
TABLE II

Cumulative hydroxyproline ${ }^{-14} \mathrm{C}$ excretion in monkeys

\begin{tabular}{|c|c|c|c|c|c|c|}
\hline \multirow[b]{2}{*}{ Monkey } & \multirow[b]{2}{*}{ Weight } & \multicolumn{3}{|c|}{$\begin{array}{l}\text { Half-lives of theoretical } \\
\text { hydroxyproline pools* }\end{array}$} & \multirow{2}{*}{$\begin{array}{l}\text { Observed } \\
\text { hypro-14C } \\
\text { excretion }\end{array}$} & \multirow{2}{*}{$\begin{array}{l}\text { Calculated } \\
\text { hypro-14C } \\
\text { excretion } \dagger\end{array}$} \\
\hline & & $P_{1}$ & $P_{2}$ & $\mathbf{P}_{\mathbf{a}}$ & & \\
\hline & $k g$ & & days & & $\begin{array}{l}\text { \% injected } \\
\text { dose }\end{array}$ & $\begin{array}{l}\% \text { injected } \\
\text { dose }\end{array}$ \\
\hline I & 4.52 & 1.8 & 2.6 & 58 & 0.29 & 0.32 \\
\hline II & 4.25 & 1.0 & 3.1 & 00 & 0.24 & 0.26 \\
\hline II I & 5.17 & 1.0 & 2.6 & 60 & 0.28 & 0.33 \\
\hline IVt & 4.76 & 1.7 & 3.4 & 49 & 0.40 & 0.45 \\
\hline$V \ddagger$ & 5.36 & 0.9 & 1.9 & 68 & 0.39 & 0.41 \\
\hline
\end{tabular}
44 days ajter proline-14 $C$ injection

* See Equation 1 in text.

+ See Equation 2 in text.

$\ddagger$ PTE from 27 to 44 days.

tivities of urinary hydroxyproline obtained on the day of sacrifice with the hydroxyproline specific activities of soluble and insoluble skin and bone collagen in the five experimental animals is presented in Table III. In all animals the specific activity of hydroxyproline in the insoluble collagen of skin and bone was three to nine times the specific activity of the hydroxyproline in the soluble collagen fractions. In control monkeys I, II, and III the specific activity of urinary hydroxyproline was $4.0,4.1$, and 4.7 times the mean specific activity of the hydroxyproline in the soluble bone collagen fractions and 81,89 , and $92 \%$ of the mean specific activity of the hydroxyproline in the insoluble bone collagen. In general, similar relations obtained between the specific activity of urinary hydroxyproline and the hydroxyproline specific activity of soluble and insoluble skin collagen.

As indicated above, there was no apparent difference between the specific activities of urinary hydroxyproline in PTE-treated monkeys IV and

TABLE III

\begin{tabular}{|c|c|c|c|c|c|c|c|}
\hline \multirow[b]{2}{*}{ Monkey } & \multicolumn{3}{|c|}{ Soluble collagen } & \multicolumn{3}{|c|}{ Insoluble collagen } & \multirow[b]{2}{*}{ Urine } \\
\hline & Skin & Femur & Humerus & Skin & Femur & Humerus & \\
\hline & \multicolumn{3}{|c|}{$d p m / \mu g$} & \multicolumn{3}{|c|}{$d p m / \mu g$} & $d p m / \mu g$ \\
\hline I & 0.27 & 0.24 & 0.29 & 0.98 & 1.09 & 1.11 & 0.89 \\
\hline II & 0.19 & 0.15 & 0.26 & 0.72 & 0.98 & 0.86 & 0.82 \\
\hline III & 0.18 & 0.22 & 0.18 & 1.11 & 1.02 & 0.99 & 0.92 \\
\hline $\mathrm{IVt}$ & 0.20 & 0.26 & 0.22 & 1.05 & 1.03 & 1.08 & 0.85 \\
\hline $\mathrm{V}+$ & 0.12 & 0.10 & 0.27 & 1.06 & 0.96 & 0.91 & 0.87 \\
\hline
\end{tabular}

Specific activity of hydroxyproline-14 $C$ in collagen and urine 44 days after proline- ${ }^{14} C$ injection* $*$ All values indicated represe
$\pm 5 \%$.
$\dagger$ PTE from 27 to 44 days. 
$\mathrm{V}$ and control animals I, II, and III. Moreover, the relationship between urinary and collagen hydroxyproline specific activities in the PTE-treated animals was similar to that of the control monkeys. The specific activities of urinary hydroxyproline in the PTE-treated animals were 80 and $93 \%$ of the mean specific activity of the insoluble bone collagen hydroxyproline and 3.5 and 4.6 times the mean specific activity of the hydroxyproline in the soluble bone collagen.

As noted previously (8), the relationships among the specific activities of various collagen fractions a month or more after a single administration of proline $-{ }^{14} \mathrm{C}$ make it possible to calculate the fractional contribution of insoluble collagen to urinary hydroxyproline $-{ }^{14} \mathrm{C}$ if one assumes that all the radioactive precursors of the hydroxyproline- ${ }^{14} \mathrm{C}$ in insoluble collagen have about the same specific activity as the hydroxyproline $-{ }^{14} \mathrm{C}$ in soluble collagen. When the observed values for the specific activity of hydroxyproline ${ }^{-14} \mathrm{C}$ in soluble collagen, insoluble collagen, and urine were substituted in the appropriate equations (8), it was found that 80,86 , and $84 \%$ of urinary hydroxyproline- ${ }^{14} \mathrm{C}$ was derived from the degradation of insoluble collagen in control monkeys I, II, and III, respectively. Similarly, 76 and $85 \%$ of the hydroxyproline- ${ }^{14} \mathrm{C}$ excreted by PTE-treated monkeys IV and V during day 44 was derived from insoluble collagen.

\section{Discussion}

Collagen is ubiquitously distributed in the tissues of the body, and within each tissue it is present in a variety of forms that have different rates of synthesis and degradation. These circumstances complicate the use of hydroxyproline excretion as an index of collagen metabolism, but the relationship between collagen metabolism and hydroxyproline excretion can be examined in some detail with appropriate isotopic techniques. As shown by a number of investigators (see 18), the soluble collagen that is extracted from tissues with cold $0.15 \mathrm{M} \mathrm{NaCl}$ is the first form of collagen labeled after a single injection of a radioactive amino acid, and it represents a relatively small pool of newly synthesized collagen molecules that are not cross-linked $(24,25)$ and that have a metabolic half-life of less than 12 hours. More concentrated electrolyte solutions extract small amounts of intermediate forms of collagen, which have somewhat longer half-lives and are partially cross-linked, but the bulk of body collagen is present in large stable pools of highly crossed-linked insoluble collagen with metabolic half-lives of about 50 days in young animals and 300 days or longer in adult animals $(8,20)$. Because of these relationships, two assumptions can be made in the type of experiment conducted here. First, it can be assumed that most of the labeling of the hydroxyproline in collagen occurs within the first few days after a single administration of proline${ }^{14} \mathrm{C}$. The validity of this assumption is supported by the rapid decrease in the specific activity of urinary proline $-{ }^{14} \mathrm{C}$ observed here as well as by studies in rats that demonstrated a rapid decrease in the specific activity of plasma proline ${ }^{-14} \mathrm{C}$ (26) and soluble collagen (18). Earlier experiments in rats (8) demonstrated that administration of large amounts of carrier proline 9 days after injection of proline $-{ }^{14} \mathrm{C}$ had no effect on the specific activity of urinary hydroxyproline $-{ }^{14} \mathrm{C}$. Secondly, because the newly synthesized forms of collagen rapidly lose most of their label, it can be assumed that a month or more after proline- ${ }^{14} \mathrm{C}$ is administered, most of the hydroxyproline $-{ }^{14} \mathrm{C}$ in the body is found in insoluble collagen and essentially all that in urine originates from the degradation of insoluble collagen. As demonstrated here and in earlier studies in rats (8), the specific activity of soluble collagen in various tissues at this time is one-third to one-tenth the specific activity of insoluble collagen, and because over $90 \%$ of body collagen is insoluble, the labile forms of collagen cannot account for more than a small fraction of the hydroxyproline $-{ }^{14} \mathrm{C}$ remaining in the animal.

As discussed previously (8), the procedures used for the extraction of the various tissues probably did not give a quantitative separation of soluble and insoluble collagen, but this technical difficulty does not significantly limit interpretation of the data, because it is only necessary to consider the specific activity of the labile and the stable pools of collagen, and under the conditions employed, the specific activity of the insoluble collagen pools would not be significantly affected by contamination with soluble collagen. It might also be noted that the difference observed in the specific activities of the soluble and insoluble collagen frac- 
tions indicates that the soluble collagen was not significantly contaminated by insoluble collagen, which may have been denatured during homogenization of the tissues.

The results presented here constitute the first application of this general approach to primates. One of the major findings is that the relationships between collagen and urinary hydroxyproline were similar to those previously demonstrated for the rat (8). In both animals the changes in specific activity of urinary hydroxyproline${ }^{14} \mathrm{C}$ suggested the presence of at least three separate pools of collagen, but as discussed previously (8) the possibility of two or more than three pools has not been excluded. The half-lives of the three major components of urinary hydroxyproline $-{ }^{14} \mathrm{C}$ in rats varied with the ages of the animals, but in general they were similar to those observed here for five monkeys. For example, in young rats the half-lives for the three major components were about 1 day, 2 to 6 days, and 50 to 100 days. Of special interest was the similarity of the calculated values for the fractional contribution of insoluble collagen to urinary hydroxyproline. In two "young adult" rats (8), it was estimated that $57 \%$ and $70 \%$ of the urinary hydroxyproline originated from the degradation of insoluble collagen; values of $80 \%, 86 \%$, and $84 \%$ were obtained for three control monkeys. The higher values obtained in the monkeys are probably explained by their older developmental ages, since the fractional contribution of insoluble collagen is larger in older animals $(8,10)$. These results appear to establish the general applicability of these techniques, and they suggest that the relationships demonstrated in rats also hold for man. We are currently investigating the feasibility of performing similar experiments in human subjects.

The observations with parathyroid hormone help to define the major site of action of the hormone on collagen. As was previously observed in man $(13,15)$, PTE increased the amount of hydroxyproline peptides in urine, indicating that the rate of collagen degradation was increased (10). In monkeys that had been given proline${ }^{14} \mathrm{C} 1$ month earlier, the amount of hydroxyproline ${ }^{-14} \mathrm{C}$ in urine also increased. Since insoluble collagen was the only possible source of hydroxy- proline $-{ }^{14} \mathrm{C}$ of relatively high specific activity, the results indicate that parathyroid hormone directly or indirectly increased the degradation of insoluble collagen. ${ }^{4}$ Although some observations suggest that PTE may affect the rate of collagen synthesis (29), several recent reports $(30,31)$ indicate that it increases the degradation of older forms of collagen in tissue cultures of bone.

The question of whether parathyroid hormone also increased the degradation of soluble collagen (11) was not fully resolved by the data. If parathyroid hormone affected only the degradation of insoluble collagen and if all the additional hydroxyproline in urine originated from insoluble collagen, the specific activity of the urinary hydroxyproline${ }^{14} \mathrm{C}$ should have increased. Calculations based on the data in Tables I and III indicate that this specific activity should have been 0.93 and $0.94 \mathrm{dpm}$ per $\mu \mathrm{g}$ in monkeys IV. and $\mathrm{V}$ instead of the observed values of 0.85 and 0.87 . Also, the calculated values for fractional contribution of insoluble collagen to urinary hydroxyproline should have been greater in the treated than in the control monkeys. The results suggest, therefore, that parathyroid hormone increased the degradation of both soluble and insoluble collagen. However, because the theoretically maximal change in urinary specific activity is small and only a limited number of observations were made, further studies are probably necessary to document fully the relative magnitude of the effect on the degradation of soluble collagen.

The results presented here do not in themselves establish that the effect of parathyroid hormone on collagen metabolism is limited to the collagen found in bone, even though studies by others make this a reasonable assumption. Investigators in two other laboratories $(26,32)$ have observed similar effects of parathyroid hormone on the excretion of hydroxyproline $-{ }^{14} \mathrm{C}$ in rats previously injected with proline $-{ }^{14} \mathrm{C}$.

4 These effects of PTE on hydroxyproline excretion probably cannot be explained by any changes in renal clearance produced by the hormone. Peptides containing hydroxyproline are rapidly cleared by the kidneys under normal conditions (27), and it has recently been demonstrated (28) that injection of PTE into the renal artery of dogs does not increase the excretion of hydroxyproline peptides until after the PTE has increased the resorption of bone. 


\section{References}

1. Avioli, L. V., and D. J. Prockop. Collagen metabolism and the response to parathyroid extract in the intact rhesus monkey. Clin. Res. 1965, 13, 545.

2. Stetten, M. R. Some aspects of the metabolism of hydroxyproline, studied with the aid of isotopic nitrogen. J. biol. Chem. 1949, 181, 31.

3. Prockop, D. J., and K. Juva. Synthesis of hydroxyproline in vitro by the hydroxylation of proline in a precursor of collagen. Proc. nat. Acad. Sci. (Wash.) 1965, 53, 661.

4. Lukens, L. N. Evidence for the nature of the precursor that is hydroxylated during the biosynthesis of collagen hydroxyproline. J. biol. Chem. 1965, 240, 1661.

5. Ziff, M., A. Kibrick, E. Dresner, and H. J. Gribetz. Excretion of hydroxyproline in patients with rheumatic and non-rheumatic diseases. J. clin. Invest. 1956, 35, 579.

6. Meilman, E., M. M. Urivetsky, and C. M. Rapoport. Urinary hydroxyproline peptides. J. clin. Invest. 1963, 42, 40.

7. Lindstedt, S., and D. J. Prockop. Isotopic studies on urinary hydroxyproline as evidence for rapidly catabolized forms of collagen in the young rat. J. biol. Chem. 1961, 236, 1399.

8. Prockop, D. J. Isotopic studies on collagen degradation and the urine excretion of hydroxyproline. J. clin. Invest. 1964, 43, 453.

9. Smiley, J. D., and M. Ziff. Urinary hydroxyproline excretion and growth. Physiol. Rev. 1964, 44, 30.

10. Prockop, D. J., and K. I. Kivirikko. Hydroxyproline and the metabolism of collagen in Treatise on Collagen, G. N. Ramachandran and B. S. Gould, Eds. London, Academic Press, vol. 2, in press.

11. Klein, L., K. Albertsen, and P. H. Curtiss, Jr. Urinary hydroxyproline in hyperparathyroidism: a study of three cases with and without bone lesions. Metabolism 1962, 11, 1023.

12. Dull, T. A., and P. H. Henneman. Urinary hydroxyproline as an index of collagen turnover in bone. New Engl. J. Med. 1963, 268, 132.

13. Keiser, H. R., J. R. Gill, Jr., A. Sjoerdsma, and F. C. Bartter. Relation between urinary hydroxyproline and parathyroid function. J. clin. Invest. 1964, 43, 1073.

14. Benoit, F. L., G. B. Theil, and R. H. Watten. Hydroxyproline excretion in endocrine disease. Metabolism 1963, 12, 1072.

15. Johnston, C. C., Jr., and W. P. Deiss, Jr. Parathyroid hormone and urinary hydroxyproline. Metabolism 1965, 14, 523.
16. Lee, C. A., and H. M. Lloyd. Urinary hydroxyproline in diseases involving bone and calcium metabolism. Med. J. Aust. 1964, 51, 992.

17. Laitinen, O., E. A. Nikkilä, and K. I. Kivirikko. Hydroxyproline in the serum and urine: normal values and clinical significance. Acta med. scand. 1966, 179, 275.

18. Jackson, D. S., and J. P. Bentley. On the significance of the extractable collagens. J. biophys. biochem. Cytol. 1960, 7, 37.

19. Van Wagenen, G., and H. R. Catchpole. Physical growth of the rhesus monkey (Macaca mulatta). Amer. J. Phys. Anthrop. 1956, 14, 245.

20. Prockop, D. J., and S. Udenfriend. A specific method for the analysis of hydroxyproline in tissues and urine. Analyt. Biochem. 1960, 1, 228.

21. Troll, W., and J. Lindsley. A photometric method for the determination of proline. J. biol. Chem. 1955, 215, 655.

22. Prockop, D. J., S. Udenfriend, and S. Lindstedt. A simple technique for measuring the specific activity of labeled hydroxyproline in biological materials. J. biol. Chem. 1961, 236, 1395.

23. MacIntyre, I. The flame-spectrophotometric determination of calcium in biological fluids and an isotopic analysis of the errors in the Kramer-Tisdall procedure. Biochem. J. 1957, 67, 164.

24. Piez, K. A., E. Weiss, and M. S. Lewis. The separation and characterization of the $\alpha$ - and $\beta$-components of calf skin collagen. J. biol. Chem. 1960, 235, 1987.

25. Veiz, A., and J. Anesey. Modes of intermolecular cross-linking in mature insoluble collagen. J. biol. Chem. 1965, 240, 3899.

26. Laitinen, O. Personal communication.

27. Prockop, D. J., H. Keiser, and A. Sjoerdsma. Gastrointestinal absorption and renal excretion of hydroxyproline peptides. Lancet 1962, 2, 527.

28. Avioli, L. V., J. E. McDonald, P. H. Henneman, and S. W. Lee. The relationship of parathyroid activity to pyrophosphate excretion. J. clin. Invest. 1966, 45, 1093.

29. Flanagan, B., and G. Nichols, Jr. Metabolic studies of human bone in vitro. II. Changes in hyperparathyroidism. J. clin. Invest. 1965, 44, 1795.

30. Stern, B. D., M. J. Glimcher, G. L. Mechanic, and P. Goldhaber. Studies of collagen degradation during bone resorption in tissue culture. Proc. Soc. exp. Biol. (N. Y.) 1965, 119, 577.

31. Kaufman, E. J., M. J. Glimcher, G. L. Mechanic, and P. Goldhaber. Collagenolytic activity during active bone resorption in tissue culture. Proc. Soc. exp. Biol. (N. Y.) 1965, 120, 632.

32. Harris, E. D., Jr., and A. Sjoerdsma. Effect of parathyroid extract on collagen metabolism. J. clin. Endocr. 1966, 26, 358. 